\title{
XIV. Reply to Mr. Cayley's remarks
}

\section{Rev. Brice Bronwin}

To cite this article: Rev. Brice Bronwin (1843) XIV. Reply to Mr. Cayley's remarks, Philosophical Magazine Series 3, 23:150, 89-91, DOI: 10.1080/14786444308644699

To link to this article: http://dx.doi.org/10.1080/14786444308644699

$$
\text { 册 Published online: } 30 \text { Apr } 2009 .
$$

Submit your article to this journal 준

LII Article views: 2

Q View related articles ¿ك 
The Rev. B. Bronwin's Reply to Mr. Cayley's Remarks. 89

In reference to the preceding table, the analogies of starch, gum and sugar are sufficiently familiar, both in the artificial processes, by which the former may be transformed into the latter, and in the changes produced by vegetation. 'The conversion of sugar and honey into wax by bees was long ago shown by Huber, and has lately been brought forward with happy effect by Liebig, in evidence of the part which the saccharine class of bodies performs in the respiratory œconomy. The intermediate position which fat holds between sugar and wax would seem to point to it as a stage in the process of reduction. The analogy between wax and cholesterin is sufficiently striking as products of reduction from an amylaceous or saccharine base; and this idea has been strengthened by the circumstance of my having obtained from the latter bodies bearing a close analogy to the turpentine and naphtha type, while the opinion has gained support, which I entertain, that cholesterin is the wax of mammiferous animals. The correspondence of resins to these bodies is sufficiently apparent.

XIV. Reply to Mr. Cayley's Remarls. By the Rev. BrICE Bron WIN"

A DESIRE to see the paper which I last transmitted to A this Journal printed before my reply to Mr. Cayley, has occasioned this delay in noticing his remarks of the 13th of April ult. (inserted in the Number for May, p. 358) on a former paper of mine. With respect to the second form of $\omega$, he says, that I by no means show that Jacobi's formulæ fail, but rather confirm them. Now I did not say that they failed for it, but only that they were reducible till it disappeared, and that with it their second members were improper representations of the first. And if this be correct, which Mr. Cayley does not deny, it is surely to be discarded from the theory.

For the other three forms, Mr. Cayley thinks that when $u=\omega, \frac{u}{\mathrm{M}}$ might be $p \mathbf{H}+p^{\prime} \mathbf{H}^{\prime} \sqrt{-1}$, and $\mathrm{s} a v= \pm 1,0$, $\pm \infty \sqrt{ }=1$, or $\pm \frac{1}{\lambda}$. I presume he means $\frac{1}{\lambda}$, not $\frac{1}{k}$. I consider that the structure of the formulæ implies that $s a \frac{u}{\mathrm{M}}$, c $a \frac{u}{\mathrm{M}}$ do not exceed the limits \pm 1 , and therefore reject * Communieated by the Author. 
$\pm \infty \sqrt{-1}$ and $\pm \frac{1}{\lambda}$. And as 0 relates to the second form of $\omega$, it is to be rejected. There is certainly room for discussion as to whether the quantities $p$ and $p^{\prime}$ are to be determined or assumed. I assumed them, and took the least values, because it did not affect my conclusions. Were I to discuss the various points to which this difference between me and Mr. Cayley gives rise, I should extend this paper to too great a length. And as I think I can place the subject in a clearer light by a much shorter process, I prefer doing so.

But first I must beg to call Mr. Cayley's attention to a real transformation at page 54 of Jacobi's work. It is derived by the aid of imaginary quantities, and from an $\omega=\frac{\mathrm{K}^{\prime} \sqrt{-1}}{n}$, and is therefore of the third form. Will Mr. Cayley be prevailed upon to make trial of it in its simplest case, or when $n=3$, and see if he find it to be a transformation? It is but right to say that $I$ have done so, and did not make it to be one. And if 1 am correct, this must be fatal to the third form of 0 .

And I nust observe, that though Jacobi has shown the possibility of such a transformation as he has given, by showing that there are sufficient equations to determine the constants, he has not shown that any and every value of w will give one. Suffice it that there is one value, or a series of values, namely those included in the first form of this quantity. Nor has he assigned any reasons for the different forms of it which he has suggested. Moreover, he has set out from an assumed equation $1-y=f(x)$, page 39 , from which all the rest of the formulæ are derived. In this assumed equation he has not actually determined the constants, but only assumed them. If they were actually determined, it might appear that they are not susceptible of that generality which their author and Mr. Cayley suppose.

M. Jacobi's formula, as Mr. Cayley has reduced them, are

$$
\begin{aligned}
& \mathrm{s} a v=\frac{\mathrm{s} a u \mathrm{~s} a(u+2 \omega) \ldots \ldots \ldots \mathrm{s} a(u+2(n-1) \omega)}{\mathrm{s} a(\mathrm{~K}-2 \omega) \mathrm{s} a(\mathrm{~K}-4 \omega) \ldots \mathrm{s} a(\mathrm{~K}-2(n-1) \omega)} \ldots(1 .) \\
& \operatorname{c} a v=\frac{\operatorname{c~} a u \operatorname{c} a(u+2 \omega) \ldots \ldots \ldots \mathrm{c} a(u+2(n-1) \omega)}{\mathrm{c} a 2 \omega \mathrm{c} a 4 \omega \ldots \ldots \text { c } a 2(n-1) \omega} \ldots(2 .)
\end{aligned}
$$

The numerator of $(1$.$) when developed is$ and that of (2.) is

$$
\text { s } a u\left(s^{2} a 2 w-s^{2} a u\right) . \ldots \ldots \ldots
$$

$$
\text { c } a u\left(\mathrm{~s}^{2} a(\mathrm{~K}-2 \omega)-\mathrm{s}^{2} a u\right) \ldots \ldots
$$


'The Rev. B. Bronwin's Reply to Mr. Cayley's Remarks. 91

These formulæ, therefore, by suitable values of $u$, are constructed to fulfil the conditions s $a v=0, \mathrm{c} a v= \pm 1$, and also s $a v= \pm 1$, c $a v=0$. And it must be possible to satisfy them both. For at page 40 , in deriving the value of $y=\mathrm{s} a v$ from that of $1-y$, Jacobi finds $y=0$ when $u=0$, $2 \omega$, \&c. And at page 41 , in finding the value of $M$, he makes $x=\mathrm{s} a u=1, y=1$. Also the values of $\lambda$ and of $1 \pm \lambda y$ depend on those of $M$ and of $y$. Both these conditions therefore are at the very foundation of Jacobi's theory.

He also makes $u, u+2 w$, \&c., and even $0,2 w, 4 w$, \&c., successive values of $u$. This decides the form of $u$. If the general form of $\omega$ be $\frac{p \mathrm{~K}+p^{\prime} \mathrm{K} \sqrt{-1}}{n}$, that of $u$ is $\frac{p \theta+p^{\prime} \theta^{\prime} \sqrt{-1}}{n} ; \theta$ and $\theta^{\prime}$ being real elliptic functions, having the common amplitude $\eta$, and the moduli $k$ and $k^{\prime}$ respectively. When $\eta=0, \frac{\pi}{2}, \pi, \& c ., \theta=0, K, 2 \mathrm{~K}, \& c_{.} ; \theta^{\prime}=0, \mathrm{~K}^{\prime}, 2 \mathrm{~K}^{\prime}, \& \mathrm{c}$; and $u=0, \omega, 2 \omega, 8 \mathrm{c}$. For the three forms of $s$ which we have to consider these values of $u$ fulfil the condition s $a v=0, \mathrm{c} a v= \pm 1$. For the first form of $\omega$, when the denominator of (1.) reduces to $\operatorname{s} a \mathrm{~s} a 3 \omega \ldots \ldots$, , the values $u=0,3 \omega$, \&c. satisfy the condition $\mathrm{s} a v= \pm 1, \mathrm{c} a v=0$ also. But for the third and fourth forms this denominator cannot be so reduced, nor can $u$ be made to take any of the forms $\mathrm{K}-2 \omega, \mathrm{K}-4 \omega$, \&c., or $2 \omega-K, 4 \omega-K$, \&c. For it could only assume them when $\eta$ has some of the values $\frac{\pi}{2}, \pi$, \&c., and consequently $\theta$ and $\theta^{\prime}$ some of the corresponding values $K, K^{\prime}, 2 \mathrm{~K}$, $2 \mathrm{~K}^{\prime}, \& \mathrm{c}$. But for none of these values will $u$ become any one of the quantities $2 r \omega-K$. The third and fourth forms of $\omega$ therefore will not fulfil the conditions to which the formula have been subjected, and consequently they must be rejected.

We might take a shorter course. It is sufficient to observe that the first form of $\omega$ only will satisfy the conditions s $a u=0$ and $s a n=1$ required by Jacobi's theory, pages 40 and 41 . Mr. Cayley says, I have brought no objection against any particular step of Jacobi's reasoning. I suppose them to be all quite correct. But any assumed form of $\omega$ will not necessarily fulfil all the required conditions. It must be remembered that these forms are assumed, not determined.

Gunthwaite Hall, June 15, 1843.

B. Bronwin. 